\title{
A rare helicobacter pylori infection-negative early gastric cancer in a young man with primary hypertrophic osteoarthropathy
}

Helicobacter pylori $(\mathrm{Hp})$ infection-negative gastric cancer is very rare [1]. We describe a rare early gastric cancer in $\mathrm{Hp}$ infection-negative gastric mucosa in a young man with primary hypertrophic osteoarthropathy, which is a rare monogenetic disease [2].

A 30-year-old man was referred to our hospital for endoscopic examination. Endoscopy revealed a whitish and laterally spread elevated lesion in the greater curvature of the upper gastric body. The size of the lesion was approx. $2.5 \times 3.0 \mathrm{~cm}$ ( Fig. 1). No atrophy or intestinal metaplasia was observed in the background gastric mucosa. The biopsy from the background mucosa showed no obvious abnormality (> Fig.2). Furthermore, both the serum $\mathrm{Hp}$ antibody and urea breath test were negative. Narrow-band imaging (NBI) with magnifying endoscopy revealed a papillary-shaped microsurface and irregular microvessels in the lesion with clear demarcation (\$ Fig.3, - Video 1). According to the vascular and surface pattern classification system [3], it was considered a cancerous lesion. Also, the biopsy showed high grade intraepithelial neoplasia (HGIN), and thus endoscopic submucosal dissection (ESD) was performed.

Histologically, the tumor glands presented papillary or tubular growth with obvious structural atypia, and the tumor cell density was significantly increased (ฉ Fig.4). Immunohistochemically, the neoplasia area was positive for MU5AC but negative for MUC6, MUC2, CD10, and $C D X-2$ expression, suggesting that the mucin genotype was gastric. The ki-67 labeling index was $10 \%$. The expression of p53 protein was negative ( Fig.5). Finally, the lesion was diagnosed as a foveolar-type adenoma with HGIN according to the World Health Organization (WHO) classification, and as a well-differentiated adenocarcinoma using the Japanese Classification of Gastric Carcinoma (JCGC) [4].
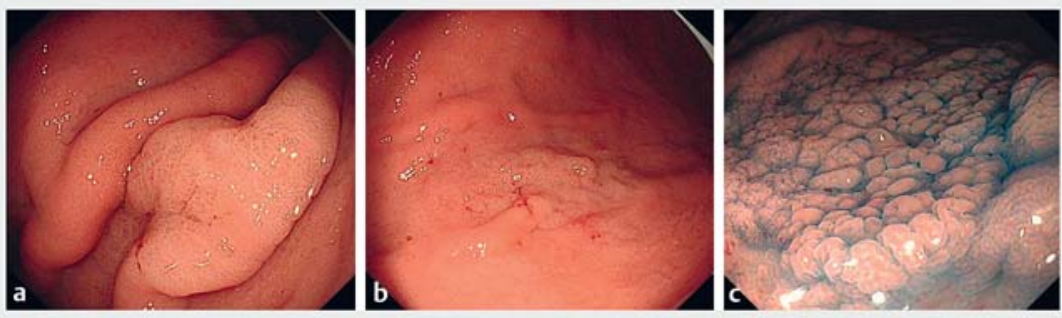

- Fig. 1 Endoscopic views of lesion. a, b A discolored and laterally spread elevated lesion, $2.5 \times 3.0 \mathrm{~cm}$ in size, in the greater curvature of the upper gastric body. $\mathbf{c}$ Indigo carmine dyeing showed clear demarcation line.
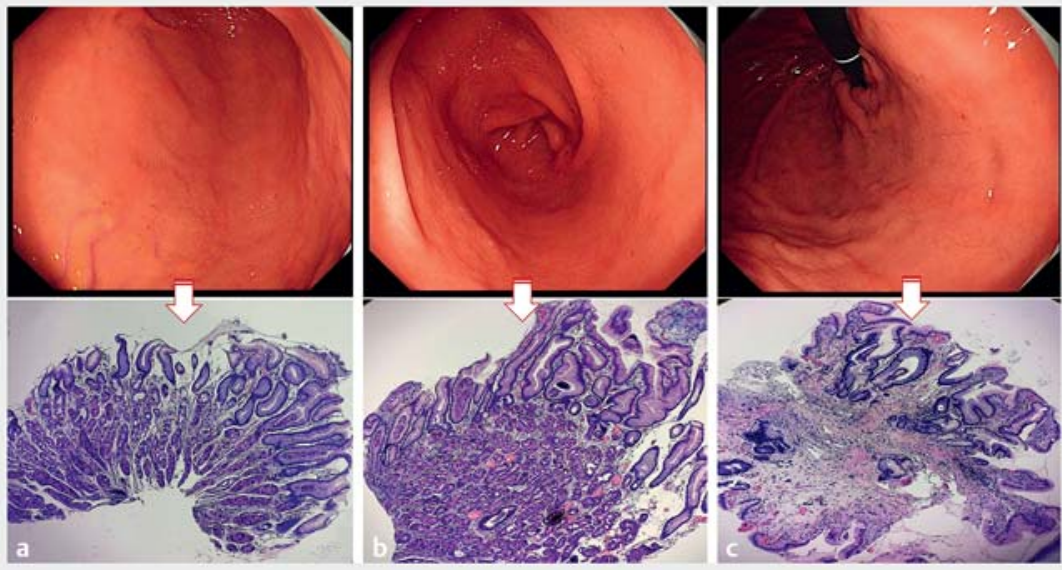

- Fig. 2 a, b, c No atrophy and intestinal metaplasia in the background gastric mucosa, and no obvious abnormality or $\mathrm{Hp}$ infection was observed in biopsies from these areas.
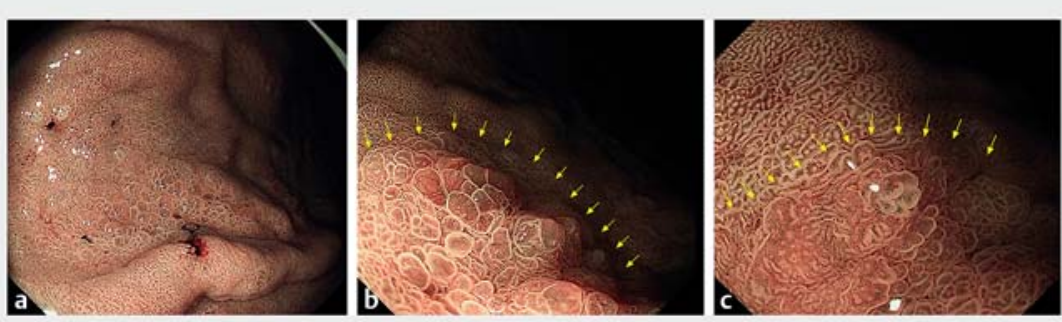

Fig. 3 a, b, c Narrow-band imaging with magnifying endoscopy showed an irregular papillary-shaped microsurface and irregular microvascular pattern. 


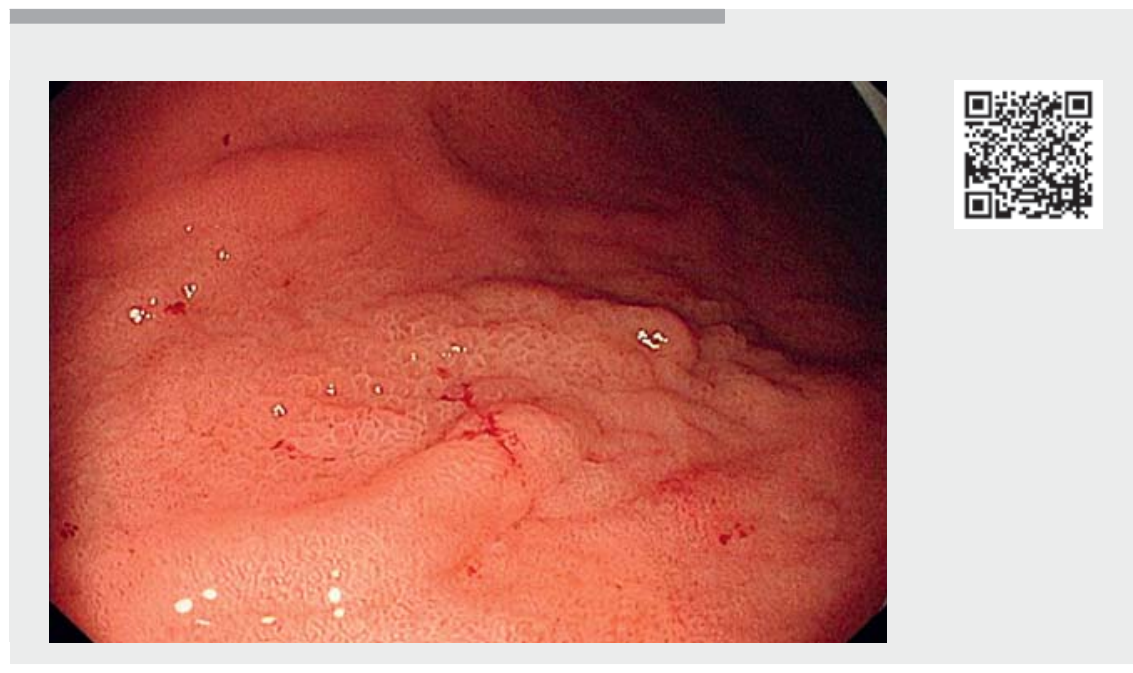

$\checkmark$ Video 1 The endoscopic characteristics of a rare foveolar-type early gastric cancer.

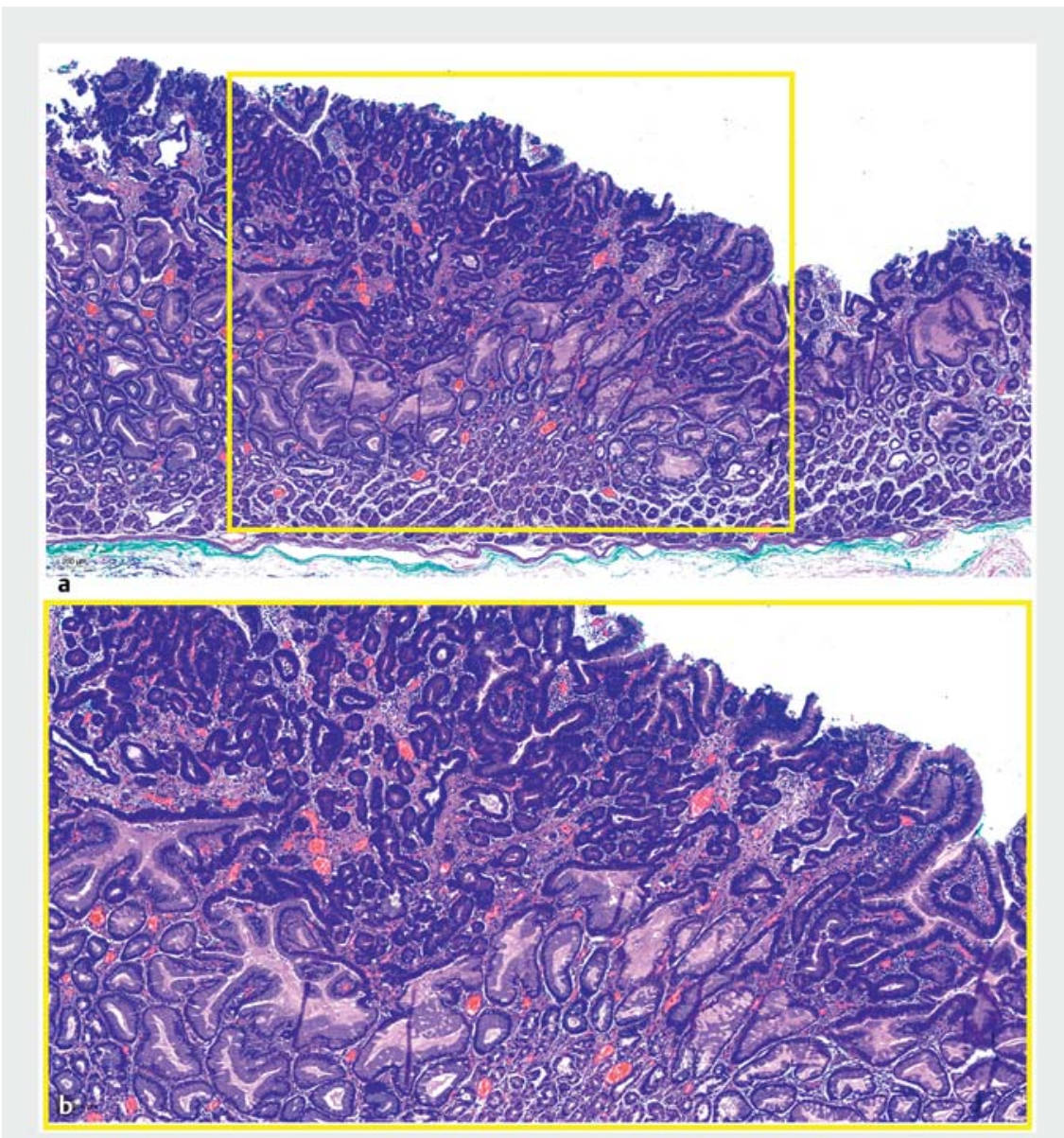

- Fig. 4 a Histological examination showed tumor glands presented papillary or tubular growth with obvious structural atypia. b The tumor cell density was significantly increased. circulating PGE2 levels, which can stimulate cell proliferation, suggesting a link between primary hypertrophic osteoarthropathy and tumors. Therefore, endoscopy should be performed to monitor the gastric neoplasia lesions in this subset of patients.

Endoscopy_UCTN_Code_CCL_1AB_2AD_3AB

Competing interests

The authors declare that they have no conflict of interest.

The authors

\section{Zhixia Dong ", Jie Xia *, Xinjian Wan}

Digestive Endoscopic Center, Shanghai Jiaotong University Affiliated Sixth People's Hospital, Shanghai, China

\section{Corresponding author}

\section{Xinjian Wan, MD}

Digestive Endoscopic Center, Shanghai Jiaotong University Affiliated Sixth People's Hospital, 600 Yishan Road, Shanghai 200233, China

slwanxinjian2020@126.com

References

[1] Mizutani T, Araki H, Saigo C et al. Endoscopic and pathological characteristics of Helicobacter pylori infection-negative early gastric cancer. Dig Dis 2020; 38: 474-483

[2] Zhang Z, Zhang C, Zhang Z. Primary hypertrophic osteoarthropathy: an update. Front Med 2013; 7: 60-64

[3] Muto M, Yao K, Kaise M et al. Magnifying endoscopy simple diagnostic algorithm for early gastric cancer (MESDA-G). Dig Endosc 2016; 28: 379-393

[4] Sato C, Hirasawa K, Tateishi Y et al. Clinicopathological features of early gastric cancers arising in Helicobacter pylori uninfected patients. World J Gastroenterol 2020; 26: 2618-2631

[5] Yamamoto Y, Fujisaki J, Omae M et al. Helicobacter pylori-negative gastric cancer: characteristics and endoscopic findings. Dig Endosc 2015; 27: 551-561
The main etiology of this disease remains unclear; it may be associated with lifestyle, gene mutations, virus infection, or an autoimmune disorder [5]. In this case, SLCO2A1 mutation was detected. An SLCO2A1 mutation results in increased 


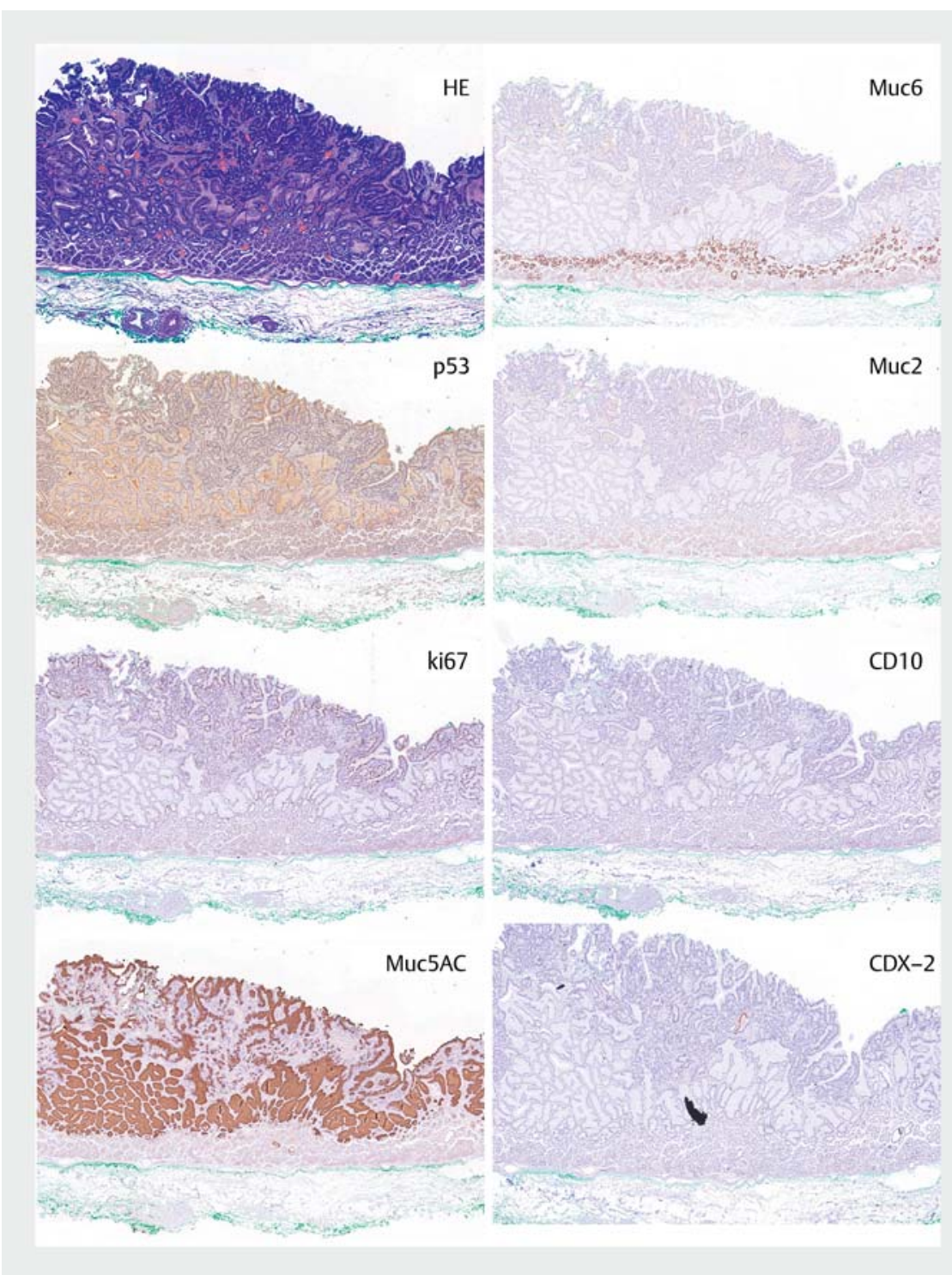

Bibliography

Endoscopy 2022; 54: E612-E614

DOI $10.1055 / \mathrm{a}-1722-2336$

ISSN 0013-726X

published online 26.1.2022

(c) 2022. Thieme. All rights reserved.

Georg Thieme Verlag KG, Rüdigerstraße 14,

70469 Stuttgart, Germany

\section{ENDOSCOPY E-VIDEOS \\ https://eref.thieme.de/e-videos}

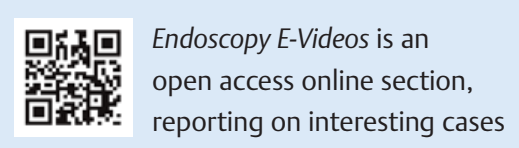
and new techniques in gastroenterological endoscopy. All papers include a high quality video and all contributions are freely accessible online. Processing charges apply (currently EUR 375), discounts and wavers acc. to HINARI are available.

This section has its own submission website at https://mc.manuscriptcentral.com/e-videos

- Fig. 5 Immunohistochemical analysis showed that the tumor cells were positive for MUC5AC, but negative for P53, MUC6, MUC2, CDX-2, and CD10 expression. 